\title{
Carcass Yield and Sensory Quality Characteristics on Post-hatch Performance of Japanese Quail as Influenced by Omega-3 Pufa Rich Oil Sources in Feed
}

\author{
G. Raj Manohar* \\ College of Poultry Production and Management, Tamil Nadu Veterinary and Animal Sciences \\ University, Hosur, India \\ *Corresponding author
}

\section{A B S T R A C T}

\begin{tabular}{|l|}
\hline K e y w o r d s \\
Japanese quail- \\
Designer foods- \\
Omega-3 PUFAs- \\
Carcass yields
\end{tabular}

The biological experiment was carried out with a total of five hundred and twenty five day old straight-run Japanese quail chicks up to 5 weeks of age. At the end of five weeks post hatch growth performance study, six birds from each treatment group were drawn randomly and subjected to humane method of slaughter. The study was conducted to assess the carcass yield on post-hatch performance of Japanese quail as influenced by supplementing Omega-3 PUFA rich oil sources like fish oil and linseed oil, independently and simultaneously at 2 and 4 per cent levels. The parameters like eviscerated carcass yield and the giblets weight viz. heart, liver and gizzard were recorded. Breast meat samples were collected from each carcass and stored at $-20^{\circ} \mathrm{C}$ for the estimation of sensory evaluation to assess the meat quality characteristics. The results of this study concluded that the effect of Omega-3 PUFA rich oils at different levels had no significant influence on ready-to-cook yield and eviscerated yield due to treatment. Also, the effect of PUFA rich oil supplementation at different levels did not alter the per cent giblets yield and the weight of heart, gizzard and liver significantly. The inclusion of omega-3 lipid sources in Japanese quail ration had no adverse effect on meat quality in terms of organoleptic assessment such as appearance, juiciness, flavour, tenderness and overall acceptability scores.

\section{Introduction}

Indian poultry industry is growing at a rapid rate to meet the increasing demand of consumers for poultry meat. Designer food or Omega-3 fatty acid enriched food refers to the food that is designed to have some health benefits other than its traditional nutritional value. In general, Fish and Linseed oils contain rich sources of Omega-3 fatty acids and may be utilized to engineer commonly consumed foods with beneficial components especially n-3 fatty acids.

Hence the present study was carried out to study the Carcass yield and sensory quality characteristics on post-hatch performance of Japanese quail as influenced by Omega-3 PUFA rich oil sources in Japanese quail ration. 


\section{Materials and Methods}

The biological experiment was carried out with five hundred and twenty five, day old straight-run Japanese quail chicks reared up to 5 weeks of age. The birds were randomly allotted into seven treatment groups as $\mathrm{T}_{1}$ (Control: without oils), $\mathrm{T}_{2}$ (2\% Fish oil), $\mathrm{T}_{3}$ ( $2 \%$ Linseed oil), $\mathrm{T}_{4}$ (4\% Fish oil), $\mathrm{T}_{5}(4 \%$ Linseed oil), $\mathrm{T}_{6}: 2 \%$ oil (1\% Fish oil $+1 \%$ Linseed oil) and $\mathrm{T}_{7}: 4 \%$ oil ( $2 \%$ Fish oil $+2 \%$ Linseed oil) with three replicates having 25 chicks in each replicate. The birds were fed with experimental diet ad libitum and had free access to potable drinking water throughout the experimental period. At the end of five weeks growth study period, six birds from each treatment group were drawn randomly and subjected to humane method (Mechanical method) of slaughter. The parameters like eviscerated carcass yield and the giblets weight viz. heart, liver and gizzard were recorded. Breast meat samples were collected from each carcass and stored at $-20^{\circ} \mathrm{C}$ for sensory evaluation to assess the quality characteristics of Japanese quail meat.

The organoleptic assessment on post-hatch performance of Japanese quail meat involved cooking of uniform sized samples of breast muscles at 15 psi for 15 minutes. The cooked breast muscles were served hot separately to a six-member semi trained taste panel.

The results were recorded on a nine point hedonic scale with ascending ratings for the desired attributes of appearance, flavour, juiciness, tenderness and overall acceptability (Panda et al., 1982). The data collected were subjected to statistical analyses as per Snedecor and Cochran (1989). Angular transformation is applied to percentages before statistical analysis wherever needed. The non-parametric values were subjected to Kruskal-Wallis non-parametric test (Sokal and Rohlf, 1995).

\section{Results and Discussion}

The mean carcass yield on post-hatch performance of Japanese quail as influenced by supplementing Omega-3 Poly Unsaturated Fatty acid (PUFA) rich oil sources independently and simultaneously in feed is presented in Table 1. Based on the results of this study, it was revealed that the effect of PUFA rich oils at different levels had no significant influence on Ready-to-cook yield and eviscerated yield due to treatment. Also, the effect of PUFA rich oil supplementation at different levels did not alter the per cent giblets yield and the weight of heart, gizzard and liver significantly.

The reports of several studies, Saricicek et al., (1997), Cortinas et al., (2004) and LopezFerrer et al., (2001) also indicated no significant difference due to Omega-3 PUFA rich oil source supplementation on ready-tocook yield of broilers.

\section{Meat quality- Organoleptic assessment}

The mean appearance, flavour, juiciness, tenderness and overall acceptability scores on post-hatch performance of Japanese quail meat as influenced by supplementing PUFA rich oil sources independently and simultaneously in feed are presented in Table 2. The supplementation of PUFA rich fish and linseed oils at different levels did not alter the organoleptic characteristics among the treatment groups.

Miller and Robisch (1969) concluded that the meat received from the broilers fed Menhaden oil had slightly less acceptable flavour and the continuous feeding of 1.5 and 2.5 per cent levels of fish oil tainted the flesh which is not in agreement with the results of this study. Lopez-Ferrer et al., (1999) reported that the meat samples of broilers fed diets with 8.2 per cent fish oil from zero to five weeks had the 
poorest sensory quality scores. Moreover, the use of fish oil in the diets at the level studied up to the period of slaughter clearly caused deterioration in the sensory quality of the cooked meat rendering their use unsuitable. Contrary to the report, incorporation of fish oil up to four per cent level did not show deterioration in sensory quality of cooked meat and taste panelists accepted the quality in this study. Similarly, Lopez-Ferrer et al., (2001b) stated that broiler meat samples did not show significant difference when supplied with varying levels of linseed oil, which is in agreement with the above research findings.

Table.1 Mean Carcass yield $(\%)( \pm$ S.E) on post-hatch Japanese quail performance as influenced by feeding OMEGA-3 PUFA rich oil sources at 5 weeks of age

\begin{tabular}{|c|c|c|c|c|c|c|}
\hline Treatment groups & $\begin{array}{c}\text { Eviscerated } \\
\text { yield }\end{array}$ & Heart & Gizzard & Liver & $\begin{array}{c}\text { Giblets } \\
\text { yield }\end{array}$ & $\begin{array}{l}\text { Ready-to- } \\
\text { cook yield }\end{array}$ \\
\hline $\mathbf{T}_{1^{-}}$Control & $71.16 \pm 0.52$ & $0.77 \pm$ & 1.96 & $2.09 \pm 0.20$ & $4.81 \pm 0.28$ & $75.97 \pm 0.53$ \\
\hline $\mathrm{T}_{2-} \mathbf{2 \%}$ Fish oil (FO) & 72. & $0.83 \pm$ & 2.11 & $2.22 \pm 0.15$ & $5.16 \pm 0.30$ & \pm 0.65 \\
\hline $\mathrm{T}_{3^{-}} \mathbf{2 \%}$ Linseed oil (LO) & & 0.8 & 2.0 & 2 & $5.13 \pm$ & 76. \\
\hline$T_{4}-4 \%$ Fish oil & 72 & 0.8 & 2.1 & $2.53 \pm$ & $5.57 \pm 0.13$ & $78.30 \pm 0.59$ \\
\hline $\mathrm{T}_{5}-4 \%$ Linseed oil & 71.6 & $0.83 \pm 0.04$ & $2.32 \pm 0.08$ & $2.27 \pm 0.19$ & $5.42 \pm 0.20$ & $77.10 \pm 0.58$ \\
\hline $\mathrm{T}_{6}-2 \%(1 \% \mathrm{FO}+1 \% \mathrm{LO})$ & $71.44 \pm 0.58$ & $0.87 \pm 0.06$ & $2.13 \pm 0.08$ & $2.48 \pm 0.16$ & $5.48 \pm 0.16$ & $76.92 \pm 0.45$ \\
\hline $\mathrm{T}_{7 .} 4 \%(2 \% \mathrm{FO}+2 \% \mathrm{LO})$ & $71.50 \pm 0.77$ & $0.92 \pm 0.05$ & $2.17 \pm 0.11$ & $2.38 \pm 0.23$ & $5.47 \pm 0.30$ & $76.98 \pm 0.59$ \\
\hline
\end{tabular}

Value within each cell is a mean of 6 observations

Table.2 Mean sensory evaluation values $( \pm$ S.E) on breast meat of post-hatch Japanese quail performance as influenced by feeding OMEGA-3 PUFA rich oil sources at 5 weeks of age

\begin{tabular}{|l|c|c|c|c|c|}
\hline \multicolumn{1}{|c|}{ Treatment groups } & Appearance & Flavour & Juiciness & Tenderness & Overall acceptability \\
\hline $\mathbf{T}_{\mathbf{1}}$ - Control & $6.67 \pm 0.92$ & $6.50 \pm 0.56$ & $6.67 \pm 0.42$ & $6.67 \pm 0.21$ & $\mathbf{6 . 3 3} \pm \mathbf{0 . 2 1}$ \\
\hline $\mathbf{T}_{\mathbf{2}} \mathbf{2 \%}$ Fish oil (FO) & $7.67 \pm 0.56$ & $7.33 \pm 0.42$ & $7.00 \pm 0.52$ & $7.33 \pm 0.42$ & $\mathbf{7 . 1 7} \pm \mathbf{0 . 4 8}$ \\
\hline $\mathbf{T}_{\mathbf{3}} \mathbf{2 \%}$ Linseed oil (LO) & $7.83 \pm 0.31$ & $7.17 \pm 0.70$ & $6.83 \pm 0.60$ & $6.67 \pm 0.33$ & $\mathbf{7 . 0 0 \pm 0 . 3 7}$ \\
\hline $\mathbf{T}_{\mathbf{4}} \mathbf{4 \%}$ Fish oil & $7.00 \pm 0.58$ & $7.00 \pm 0.37$ & $7.67 \pm 0.42$ & $7.67 \pm 0.21$ & $\mathbf{7 . 3 3 \pm 0 . 2 1}$ \\
\hline $\mathbf{T}_{\mathbf{5}} \mathbf{4 \%}$ Linseed oil & $6.83 \pm 0.40$ & $6.67 \pm 0.84$ & $6.83 \pm 0.31$ & $6.17 \pm 0.48$ & $\mathbf{6 . 6 7 \pm 0 . 3 3}$ \\
\hline $\mathbf{T}_{\mathbf{6}} \mathbf{2}$ \% (1\% FO+1\%LO) & $7.83 \pm 0.40$ & $7.33 \pm 0.33$ & $7.50 \pm 0.56$ & $7.33 \pm 0.67$ & $\mathbf{7 . 0 0 \pm 0 . 3 7}$ \\
\hline $\mathbf{T}_{\mathbf{7}} \mathbf{4}$ \% (2\%FO+2\%LO) & $\mathbf{7 . 0 0} \pm \mathbf{0 . 5 8}$ & $\mathbf{7 . 0 0} \pm \mathbf{0 . 4 5}$ & $\mathbf{7 . 3 3} \pm \mathbf{0 . 4 9}$ & $\mathbf{6 . 8 3} \pm \mathbf{0 . 6 0}$ & $\mathbf{6 . 8 3} \pm \mathbf{0 . 6 5}$ \\
\hline
\end{tabular}

Value within each cell is a mean of 6 observations

Lin-Jeun-Horng et al., (2002) reported that supplementation of two and four per cent fish oil in broiler diets did not significantly increase fishy flavour of meat samples (or) adversely affect $(\mathrm{P}>0.05)$ the acceptability of chicken frankfurters which coincides with the results obtained in this study. Bou et al., (2004) observed no significant difference in consumer acceptability of meat samples received from the broiler fed diets enriched with 1.25 and 2.50 per cent fish oil after five months of storage at $-20^{\circ} \mathrm{C}$ or with respect to a freshly cooked commercial sample used as a blind control which is in accordance with the result of this study.

Komprda et al., (2003) stated that the enrichment of turkey meat with n-3 PUFA using either fish oil or linseed oil in the amount of 5 per cent of the feed mixture 
cannot be recommended due to the unacceptable flavour and odour of the product which is not in accordance with the result of the study.

The statistical analysis failed to show significant effect due to dietary treatments on breast meat juiciness score of post-hatch Japanese quail. The breast meat received from the birds, which received four per cent fish oil, had the numerically highest juiciness score when compared to meats obtained from the other groups.

Though variation was observed in flavour scores in breast meat of post-hatch Japanese quail, the statistical analysis failed to reveal significant effect due to dietary treatments. However, the breast meat harvested from the birds received two per cent fish oil and two per cent fish and linseed oil combination recorded highest flavour score. Saricicek et al., (1997) suggested that fish oil can be incorporated up to 0.83 per cent in starter diet; 1.14 per cent in finisher diets or fish oil can replace up to 25 per cent of the vegetable oil in the diet without affecting the flavour of the meat. Contrary to this report, the taste panelists of this study accepted the flavour of meat from the birds consumed up to four per cent fish oil in the diet.

It was concluded that the effect of Omega-3 Polyunsaturated fatty acid rich (PUFA) rich oils at different levels had no significant difference on Ready-to-Cook yield and eviscerated yield and per cent giblets yields significantly. Supplementation of n-3 PUFA rich oil sources at graded level in post-hatch Japanese quail diet had no significant effect on breast meat tenderness score. However, breast meat from the birds received four per cent fish oil had the highest tenderness score when compared to other treatment groups. The incorporation of n-3 PUFA rich oil sources in post-hatch Japanese quail diet failed to show significant difference on the overall acceptability score of breast meat. However, the breast meat obtained from the post hatch birds received four and two per cent fish oil recorded the highest overall acceptability score when compared to breast meat obtained from the birds received other treatments.

\section{References}

Bou, R., Guardiola, F. Tres, A. Barroeta, A.C. and Codony, R. 2004. Influence of dietary fat source, $\alpha$-tocopherol and ascorbic acid supplementation on sensory quality of dark chicken meat. Poult. Sci., 83: 282-292.

Cortinas, L., Villaverde, C. Galobart, J. Baucells, M.D. Codony, R. and Barroeta, A.C. 2004. Fatty acid content in chicken thigh and breast as affected by dietary polyunsaturation level. Poult. Sci., 83: 1155-1164.

Komprda, T., Zelenka, J. Drobna, Z. Jarosova A. and Faj Moinova, E. 2003. Sensory quality of meat of turkeys fed the diet with sunflower, linseed or fish oil. Archiv fur Geflugelkunde, 67(5): 225230. (Poult.Abstr., 2004, 30(2) : 424).

Lin-Jeun-Horng, Lin Yuan-Hui and Kuo Chun-Chin, 2002. Effect of dietary fish oil on fatty acid composition, lipid oxidation and sensory property of chicken frankfurters during storage. Meat Science, 60: 161-167.

Lopez-Ferrer, S., Baucells, M.D., Barroeta, A.C. and Grashorn, M.A.1999. n-3 enrichment of chicken meat using fish oil: Alternative substitution with rapeseed and linseed oils. Poult. Sci., 78: 356 - 365.

Lopez-Ferrer, S., Baucells, M.D., Barroeta, A.C., Galobart, J. and Grashorn, M.A. 2001. n-3 enrichment of chicken meat. 2. Use of precursors of long-chain polyunsaturated fatty acids: Linseed oil. 
Poult.Sci., 80: 753 - 761.

Miller, D and P.Robisch, 1969. Comparative effect of Herring, Menhaden and Safflower oils on broiler tissues fatty acid composition and flavor. Poult.Sci., $48: 2146-2157$.

Panda, B., Pandey, N.K. Mahapatra, C.M. Verma, S.S. Shrivastav A.K. and Chaudhuri D. 1982. Laboratory manual on post harvest technology of avian products, Avian products technology section, Central Avian Research Institute, Izatnagar, U.P., India.
Saricicek, B.Z., Ocak, N. and Garipoglu, A.V. 1997. A study on utilizing fish oil in broiler diets. Ziraat Fakultesi Dergisi, 12(1):33-42 (Poult.Abstr., 1998, 24(7): 2068).

Snedecor,G.W. and Cochran, W.G. 1989. Statistical methods. $8^{\text {th }}$ ed. Iowa State University Press / Ames, Iowa - 50010.

Sokal, R.R. and Rohlf, F.J. 1995. Biometry: The principles and practices of statistics in biological research.3rd ed., W.H. Freeman and company, New York, pp. $423-427$.

\section{How to cite this article:}

Raj Manohar, G. 2020. Carcass Yield and Sensory Quality Characteristics on Post-hatch Performance of Japanese Quail as Influenced by Omega-3 Pufa Rich Oil Sources in Feed. Int.J.Curr.Microbiol.App.Sci. 9(11): 3625-3629. doi: https://doi.org/10.20546/ijcmas.2020.911.434 